\title{
Evaluation of Amniotic Fluid Volume using Single Deepest Pocket Method
}

\author{
Abishek Menon ${ }^{1}$, Basavaraj N. Biradar ${ }^{2}$, Anston Vernon Braggs ${ }^{3}$, Mahesh $^{4}$ \\ ${ }^{1}$ Resident, Department of Radiodiagnosis, ${ }^{2}$ Assistant Professor, Department of Radiodiagnosis, ${ }^{3}$ Senior Resident, Department \\ of Radiodiagnosis, ${ }^{4}$ Senior Resident, Department of Radiodiagnosis, Father Muller Medical College Hospital, Mangalore, \\ Karnataka, India
}

Corresponding author: Dr Basavaraj N. Biradar, Assistant Professor, Department Of Radiodiagnosis, Father Muller Medical College Hospital, Kankanady, Mangalore - 575002, Karnataka, India

DOI: http://dx.doi.org/10.21276/ijcmsr.2019.4.4.19

How to cite this article: Abishek Menon, Basavaraj N. Biradar, Anston Vernon Braggs, Mahesh. Evaluation of amniotic fluid volume using single deepest pocket method. International Journal of Contemporary Medicine Surgery and Radiology. 2019;4(4):D81-D83.

\section{A B S T R A C T}

Introduction: Single deepest pocket provides quick assessment of AFV, as it consumes less time. It is also the only quantitative method of assessment of AFV in multiple pregnancies. However, when AFV is abnormal perinatal mortality and morbidity is increased. The perinatal mortality was 2 fold more in pregnancies with increased liquor in comparison to pregnancies with normal amniotic fluid. Study aimed to compare the use of the AFI with Single largest pocket during fetal surveillance for the prevention of adverse perinatal outcomes.

Material and Methods: 100 patients with pregnancies at gestational age between 37-40 weeks of gestation where included prospectively and scanned once. Analysis of sensitivity and specificity of single largest pocket with regards to polyhydramnios, oligohydramnios and euhydraminos were assessed keeping AFI as the standard method. later compared to perinatal outcome of the patients when estimated by both the methods.

Results: On comparison of the test group single largest pocket oligo or poly with the Gold standard AFI the test group has a sensitivity of $48 \%$ and specificity of $78.7 \%$. The test has a positive predictive value of $42.9 \%$ and Negative predictive value of $81.9 \%$. The test and the gold standard agree on 71 out of 100 having a diagnostic accuracy of $71 \%$. The Kappa value of 0.256 indicates Moderate agreement with a $\mathrm{p}$ value of 0.019 .

Conclusion: The single deepest vertical pocket is a better method of amniotic fluid volume assessment over amniotic fluid index. amniotic fluid index increases the rate of diagnosis of oligohydramnios and the rate of induction of labor without improvement in peripartum outcome.

Keywords: SLP, AFI, AFV

\section{INTRODUCTION}

Amniotic fluid provides a protective environment for fetal development during pregnancy. A decreased amniotic fluid volume (oligohydramnios) can occur because of fetal anomalies, intrauterine growth restriction, pre-eclampsia or prolonged (post-term) pregnancy. Many caregivers practice planned delivery by induction of labor or caesarean section after diagnosis of decreased amniotic fluid volume at term, to prevent an adverse pregnancy outcome. Ultrasonography is non-invasive and is used widely for the follow up of pregnancy. It can be used to determine amniotic fluid volume by measuring either the amniotic fluid index or single deepest vertical pocket. ${ }^{1}$

Adequate amniotic fluid volume (AFV) is necessary for fetal growth monitoring and wellbeing and its assessment is taken as an important variable in fetal biophysical profile ${ }^{2}$.

Abnormal amount or appearance of fluid could be an indirect sign of fetal hypoxia, neural tube defect and can help in making pregnancy management decision. ${ }^{3}$
Single deepest pocket provides quick assessment of AFV, as it consumes less time. It is also the only quantitative method of assessment of AFV in multiple pregnancies, especially in dizygotic gestations.

however, when AFV is abnormal perinatal mortality and morbidity is increased. The perinatal mortality was 2 fold more in pregnancies with increased liquor in comparison to pregnancies with normal amniotic fluid. ${ }^{4}$

Amniotic fluid volume is a component of Biophysical profile (BPP) and BPP is used for mangement of pregnancies with adverse outcome.

Invasive methods such as indicator dilution techniques are the most accurate measures of $\mathrm{AFV}$, but are impractical for clinical use. Ultrasound is noninvasive and hence it is used widely for the follow-up of pregnancy. Additionally, it can be performed serially in cases of suspected abnormal AFV. ${ }^{5}$

Study aimed to compare the use of the AFI with Single lagest pocket during fetal surveillance for the prevention of adverse perinatal outcomes. 


\section{MATERIAL AND METHODS}

This was a prospective study carried out on singleton patients above 18years of age referred to radiology department, father Muller medical collage for term scan (37-42 week of gestation) amniotic fluid volume is estimated by amniotic fluid index(AFI) and by single deepest pocket (SDP). All the patients were assessed at one sitting.

Amniotic fluid volume by ultrasound (semi quantitative method) was done using Amniotic fluid index AFI (cm) which is taken as standard. Done by dividing the abdomen into 4 quadrants, measuring the largest pocket in the 4 areas devoid of umbilical cord or fetal parts is measured and summing these areas. The usual accepted values are $5-25 \mathrm{cms}$ is considered normal, a $\mathrm{AFI}<5$ is considered oligohydramnios, AFI $>25$ is considered polyhydramnios. ${ }^{3}$

This study was compared to amniotic fluid volume estimation by single deepest pocket(SLP) .it was performed by assessing a maximal depth of amniotic fluid which is free of umbilical cord. ${ }^{4}$ The usual accepted values are $<2 \mathrm{cms}$-indicative of oligohydramnios, 2-8 cms -normal and $>8 \mathrm{cms}$ indicative of polyhydramnios. The patients were grouped into having AFV as oligohydramnios, euhydraminos and polyhydramnios. Later there outcome were compare to perinatal outcome. Perinatal outcome includes admission to a neonatal intensive care unit, an Apgar score of less than 7 at 5 minute or cesarean delivery.

\section{Inclusion criteria}

All singleton pregnancy who have completed 37 weeks according to last menstrual period and up to 42 weeks

\section{Exclusion criteria}

1. Multiple pregnancies

2. Pregnancy gestation less than 37 weeks or more than 42 weeks

3. Those not giving consent for participating in the study

\section{RESULT}

In our present study out of 100 patients 13 patients were detected having oligohydramnios, 75 patients had normal amniotic fluid volume and 12 had polyhydramnios and by single largest pocket method 7 patients had polydraminos, 83patients had normal amniotic fluid and 10 patients had oligohydramnios. On comparison of the test group single largest pocket oligo or poly with the Gold standard of gold standard AFI the test group had a sensitivity of $48 \%$

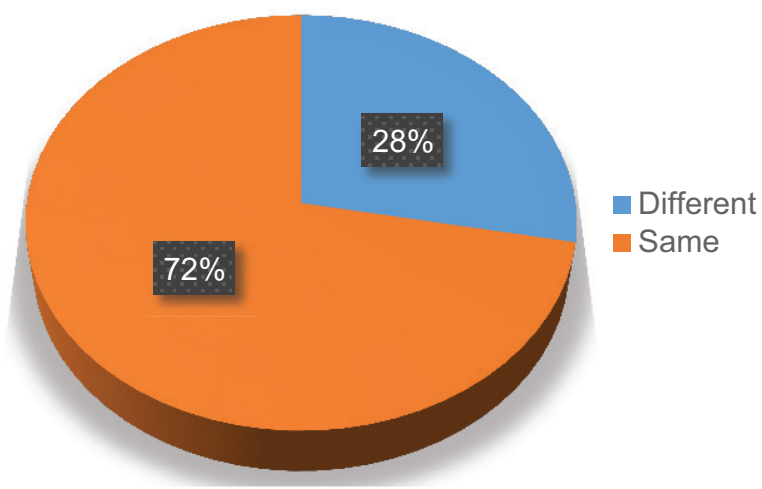

Figure-1: SLP VS AFI and specificity of $78.7 \%$. The test had a positive predictive value of $42.9 \%$ and Negative predictive value of $81.9 \%$. The test and the gold standard agree on 71 out of 100 having a diagnostic accuracy of $71 \%$. The Kappa value of 0.256 indicates Moderate agreement with a $\mathrm{p}$ value of 0.019 .

When compared perinatal outcome of patients when assessed with AFI out of 25 patients with oligo and polyhydramnios 10 had poor perinatal outcome when compared to Single largest pocket out of 14 patients having oligo and polyhydramnios 10 patients had poor perinatal outcome

\section{DISCUSSION}

Amniotic fluid is an important indicator for fetal development during pregnancy. A decreased amniotic fluid volume (oligohydramnios) can lead to fetal anomalies, intrauterine growth restriction, pre-eclampsia or prolonged (post-term) pregnancy. ${ }^{5}$

Ultrasonography is non-invasive and is used widely for the follow up of pregnancy. It can be used to analyze amniotic fluid volume by measuring amniotic fluid index or single deepest vertical pocket. Practice planned delivery by induction of labor or caesarean section after diagnosis of decreased amniotic fluid volume at term, to prevent an adverse pregnancy outcome. ${ }^{6}$ Obstetricians plan delivery by induction of labor or caesarean section after diagnosis of decreased amniotic fluid volume at term, to prevent an adverse pregnancy outcome. ${ }^{7}$

The method of amniotic fluid volume estimation using the amniotic fluid index increased the number patients who were diagnosed with oligohydramnios and polyhydramnios which in turn leads to an abnormal fluid volume when compared with the single largest pocket measure.

In a study by Alfirevic ${ }^{8}$ et al 490 patients where considered showed that a significantly greater number of patients were considered to have oligohydramonos when amniotic fluid index was used than with single largest pocket.

\section{CONCLUSION}

The single deepest vertical pocket is a better method of amniotic fluid volume assessment over amniotic fluid index. amniotic fluid index increases the rate of diagnosis of oligohydramnios and the rate of induction of labor without improvement in peripartum outcomes. Single largest pocket method takes lesser amount of time A systematic review using both the methods for accuracy of both the methods in detecting oligohydramnios is required.

\section{REFERENCES}

1. Rashid SQ.Amniotic fluid volume assessment using the single deepest pocket technique in Bangladesh. Journal of Medical Ultrasound. 2013;21(4):202-6.

2. Magann EF, Sanderson M, Martin JN, Chauhan S. The amniotic fluid index, single deepest pocket, and twodiameter pocket in normal human pregnancy. American journal of obstetrics and gynecology. 2000;182(6):15818.

3. Phelan JP, Smith CV, Broussard P, Small M. Amniotic fluid volume assessment with the four-quadrant technique at 36-42 weeks' gestation. The Journal of reproductive medicine. 1987;32(7):540-2. 
4. Nabhan AF, Abdelmoula YA. Amniotic fluid index versus single deepest vertical pocket as a screening test for preventing adverse pregnancy outcome. Cochrane Database Syst Rev. 2008;(3):CD006593.

5. Chauhan SP, Doherty DD, Magann EF, Cahanding F, Moreno F, Klausen JH. Amniotic fluid index vs single deepest pocket technique during modified biophysical profile: a randomized clinical trial. American journal of obstetrics and gynecology. 2004;191(2):661-7.

6. Miyamura T, Masuzaki H, Miyamoto M, Ishimaru T. Comparison between the single deepest pocket and amniotic fluid index in predicting fetal distress in small-for-gestational age fetuses. Acta obstetricia et gynecologica Scandinavica. 1997;76(2):123-7.

7. Rosati P, Guariglia L, Cavaliere AF, Ciliberti P, Buongiorno S, Ciardulli A, Cianci S, Vitale SG, Cignini P, Mappa I. A comparison between amniotic fluid index and the single deepest vertical pocket technique in predicting adverse outcome in prolonged pregnancy. Journal of prenatal medicine. 2015;9(1-2):12.

8. Alfirevic Z, Luckas M, Walkinshaw SA, McFarlene M, Curran R. A randomized comparison between amniotic fluid index and maximum pool depth in the monitoring of post-term pregnancy. Neonatal Intensive Care. 1997; 10(4):30-4.

Source of Support: Nil; Conflict of Interest: None

Submitted: 10-09-2019; Accepted: 30-09-2019; Published online: 13-11-2019 